\title{
Fabrication of Mushroom-Like Nanostructures on Stainless Steel Surface by Combination of Heat Treatment and Electrochemical Etching
}

\author{
Takayoshi Yano ${ }^{1, *}$, Shin Ishikawa ${ }^{1}$ and Hiroki Habazaki ${ }^{2}$ \\ ${ }^{1}$ Steel Research Laboratory, JFE Steel Corporation, Chiba 260-0835, Japan \\ ${ }^{2}$ Division of Applied Chemistry, Faculty of Engineering, Hokkaido University, Sapporo 060-8628, Japan
}

\begin{abstract}
Highly functional and multifunctional material surfaces may be created through fabrication of unusual surface structures. We fabricated mushroom-like nanostructures on a stainless steel surface by simple processes: heat treatment under an atmosphere of low partial pressure of oxygen, followed by electrochemical etching. Island-like titanium oxide was formed on the Ti-containing stainless steel surface by selective oxidation during heat treatment. The titanium oxide became the cap part of the mushroom-like nanostructure and the stem part was fabricated by selective dissolution during electrochemical etching. Detailed analysis revealed that the cap part of the mushroom-like nanostructure was mainly composed of $\gamma-\mathrm{Ti}_{3} \mathrm{O}_{5}$, and the stem part was composed of the stainless steel substrate. The contact resistance was significantly reduced by the fabrication of the mushroom-like nanostructures. The protrusions of electrically conductive $\gamma-\mathrm{Ti}_{3} \mathrm{O}_{5}$ can contribute to the reduction of the contact resistance. The mushroom-like nanostructures improved the hydrophilicity of the surface without fluorine coating, but improved the hydrophobicity of the fluorine-coated surface. The contact between the stainless steel surface and the water droplet was in the Wenzel state. [doi:10.2320/matertrans.MT-M2021013]
\end{abstract}

(Received January 27, 2021; Accepted March 31, 2021; Published May 14, 2021)

Keywords: stainless steel, heat treatment, electrochemical etching, gamma-trititanium-pentoxide, contact resistance, hydrophilic, hydrophobic

\section{Introduction}

Stainless steel is widely used in automobiles, chemical and food plants, building materials, kitchen equipment, and home appliances because of its beautiful appearance, excellent corrosion resistance, high temperature strength, and good formability. As the variety of products using stainless steel has increased in recent years, further enhancements in stainless steel properties and functionality are needed.

For example, stainless steel is increasingly being used for the bipolar plates in polymer electrolyte fuel cells. However, stainless steel has a passive film on its surface, which causes a high contact resistance between the stainless steel and carbon paper. The contact resistance can be reduced by applying electrically conductive coatings such as carbonbased materials to the stainless steel surface. ${ }^{1)}$ However, surface morphology is another important factor affecting the contact resistance. Kraytsberg et l. $^{2)}$ reported that the contact area between the stainless steel and carbon paper changes significantly depending on the surface morphology, which then affects the contact resistance.

Further, by controlling hydrophilicity, hydrophobicity and oleophobicity, various functions such as self-cleaning, ${ }^{3,4)}$ anti-fouling, ${ }^{5,6)}$ anti-fogging, ${ }^{7)}$ antibacterial, ${ }^{8)}$ anti-icing, ${ }^{9)}$ fluid friction reduction, ${ }^{10,11)}$ and corrosion resistance ${ }^{12)}$ can be provided to the material surface. It is known that the surface free energy and surface morphology greatly affect the hydrophilicity and hydrophobicity of the material surface. For example, to improve hydrophobicity, applying an organic substance to the material surface is effective; the organic substance (such as a fluorine-based polymer) has a low surface free energy. ${ }^{13)}$ However, fabricating a unique morphology on the material surface is another important approach. Tuteja et al. ${ }^{14,15)}$ showed that fabrication of a re-

*Corresponding author, E-mail: ta-yano@jfe-steel.co.jp entrant structure on the material surface is an effective way to produce a superomniphobic surface. A variety of re-entrant structures have been proposed. For example, fabrication of submicron- to submillimeter-sized mushroom-like structures has been reported to yield superomniphobic surfaces. ${ }^{16-21)}$ Fabrication of micro-nano hierarchical structures on stainless steel surfaces was also reported. ${ }^{22-24)}$

In these reports, electrically conductive or superomniphobic surfaces have been obtained by surface finishes using plasma-assisted CVD, ${ }^{1)}$ micro electrical discharge machining ${ }^{16)}$ micromolding, ${ }^{17)}$ nanotransfer molding and controlled wet etching, ${ }^{18)}$ laser ablation and electrodeposition, ${ }^{19)}$ photolithography and electroplating, ${ }^{20)}$ sputtering and anodizing and chemical etching, ${ }^{21)}$ and chemical and electrochemical etching and anodizing. ${ }^{22)}$ However, these techniques require specialized equipment and materials, and they are complicated processes. Furthermore, in etching, chemicals such as hydrofluoric acid ${ }^{23)}$ or long etching times of $10 \mathrm{~min}^{24)}$ or more may be disadvantages in terms of safe, efficient manufacturing. From the aforementioned reports, the material surface can be made highly functional and multifunctional by various techniques. However, these high cost complicated processes can be difficult to use in mass production.

Generally, stainless steel sheet is manufactured by casting a molten steel with adjusted composition, rolling, heattreating, and removing the oxide scale by electrolytic pickling or soaking in an acidic solution. In this study, we report the fabrication of unique mushroom-like nanostructures on the stainless steel surface by simple processes using a combination of conventional manufacturing processes to create a highly functional and multifunctional surface.

The concept of the fabrication process of mushroom-like nanostructures on the stainless steel surface is schematically illustrated in Fig. 1. SUS443J1, which is a Ti-containing stainless steel, is used in this study to generate nanostructures by selective oxidation of $\mathrm{Ti}$. $\mathrm{Ti}$ is more susceptible to oxidation than are $\mathrm{Cr}$ or $\mathrm{Fe}$, and titanium oxide is chemically 

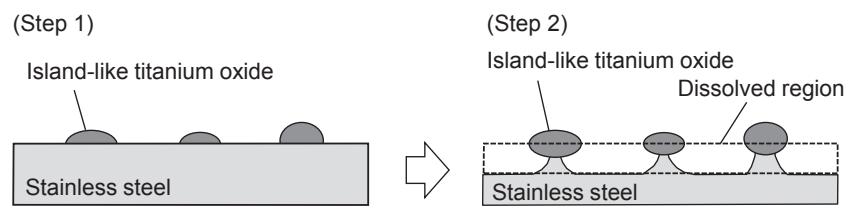

Fig. 1 Schematic illustrations of fabrication process for mushroom-like nanostructures on the stainless steel surface. Step 1: Island-like titanium oxide is formed by heat treatment. Step 2: Mushroom-like nanostructures are fabricated by electrochemical etching.

stable, being suitable for the cap material of the mushroomlike nanostructure. In step 1, the stainless steel is heat treated under an atmosphere with a low partial pressure of oxygen to form titanium oxide islands on the stainless steel surface. In step 2, using the titanium oxide island formed in step 1 as an insulating mask, the stainless steel substrate is selectively dissolved by electrochemical etching to fabricate the stem part of the mushroom-like nanostructure. We controlled the surface oxidation morphology during heat treatment and the nature of dissolution during electrochemical etching, to produce the mushroom-like nanostructures. In addition, the contact resistance and the water contact angle were examined with the expectation that the stainless steel surface having mushroom-like nanostructures would be highly functional and multifunctional.

\section{Experimental Procedure}

\subsection{Stainless steel}

SUS443J1 (Mass percentages of C: 0.006, Si: 0.17, Mn: 0.14, P: 0.027, S: 0.002, Al: 0.03, Cr: 20.77, Ti: 0.30, Cu: 0.43 , balance $\mathrm{Fe}$ ) was used as the Ti-containing stainless steel substrate. It is widely used in various applications because of its good corrosion resistance equivalent to that of SUS304. ${ }^{25)}$ A $200 \mathrm{~mm}$ thick slab of stainless steel with the above composition was prepared by continuous casting. The slab was heated, hot-rolled to $4 \mathrm{~mm}$ thick, annealed, and pickled. It was then cold-rolled to $0.3 \mathrm{~mm}$ thick, annealed, pickled, and finally cold-rolled further to $0.09 \mathrm{~mm}$ thick.

\subsection{Heat treatment}

The heat treatment was carried out using a tubular furnace and a continuous furnace under the conditions shown in Table 1. The gas composition for all conditions was $75 \mathrm{vol} \%$ $\mathrm{H}_{2}-25$ vol\% $\mathrm{N}_{2}$ to selectively oxidize $\mathrm{Ti}$ and suppress the oxidation of $\mathrm{Fe}$ and $\mathrm{Cr}$. The partial pressure of oxygen was controlled by a dew point.

\subsection{Electrochemical etching}

Electrochemical etching was carried out using a twoelectrode cell under the following conditions. $30 \mathrm{~g} / \mathrm{L}$ sulfuric acid solution ( $\mathrm{pH} 0.6)$ was used as an electrolyte at $40^{\circ} \mathrm{C}$. A constant current density of $0.5 \mathrm{~A} \mathrm{dm}^{-2}$ was applied for 5 $80 \mathrm{~s}$. A type 304 stainless steel plate was used as a counter electrode. Potential measurement during electrochemical etching was carried out using a three-electrode cell, containing an $\mathrm{Ag} / \mathrm{AgCl} /$ sat. $\mathrm{KCl}$ reference electrode and a platinum wire counter electrode. The mass loss of the specimens after electrochemical etching was measured using
Table 1 Heat-treatment conditions (a)-(d). Cooling rate: Average from maximum temperature to about $500^{\circ} \mathrm{C}$.

\begin{tabular}{lcccccc}
\hline & & \multicolumn{5}{c}{ Heating } \\
Con- & & Heating & Maximum & time at & Cooling & Dew \\
dition & Furnace & rate & temperature & maximum & rate & point \\
& & $/{ }^{\circ} \mathrm{C} \mathrm{s}^{-1}$ & $/{ }^{\circ} \mathrm{C}$ & temperature & $/{ }^{\circ} \mathrm{C} \mathrm{s}^{-1}$ & $/{ }^{\circ} \mathrm{C}$ \\
& & & & & $/ \mathrm{s}$ & \\
\hline (a) & Tubular & 3 & 920 & 5 & -59 & -18 \\
(b) & Tubular & 3 & 950 & 5 & -37 & -45 \\
(c) & Tubular & 3 & 920 & 5 & -59 & -68 \\
(d) & Continuous & 46 & 948 & 1 & -39 & -44 \\
\hline
\end{tabular}

an electronic balance. Five specimens were measured for each condition.

\subsection{Characterizations}

The specimen surfaces were observed by using JEOL JSM-7001F and JSM-7100F field emission scanning electron microscopes (FE-SEM) operated at $3 \mathrm{kV}$. Cross-sections of the specimens were observed and analyzed by using a JEOL JEM-2010F field emission scanning transmission electron microscope (FE-STEM) equipped with an energy dispersive $\mathrm{X}$-ray spectrometer (EDX) operated at $200 \mathrm{kV}$, and a Hitachi High-Tech, HF-2000 field emission transmission electron microscope (FE-TEM) operated at $200 \mathrm{kV}$. Furthermore, the composition and the crystal structure of the mushroom-like nanostructure were analyzed by using a JEOL JEMARM200F spherical aberration corrected STEM equipped with EDX and electron energy loss spectroscopy (EELS) facilities. The following crystal structure data were used to analyze the electron diffraction pattern: $\gamma-\mathrm{Ti}_{3} \mathrm{O}_{5}$ (PDF No. 00-040-0806) and $\mathrm{Cr}_{2} \mathrm{O}_{3}$ (PDF No. 00-038-1479). A focused ion beam system (FEI, Versa 3D) was used to prepare thin samples for TEM analysis. Surface conductive coatings of carbon and gold were used for morphological observation and composition and structure analysis, respectively. The surface protection coating was carbon, and the sample supports for TEM were either copper, nickel or molybdenum mesh.

The surface composition of the stainless steel was analyzed with a ULVAC, X-tool X-ray photoelectron spectrometer (XPS), using an $\mathrm{Al} \mathrm{K} \alpha$ source at a voltage of $15 \mathrm{kV}$, with a beam diameter of $100 \mu \mathrm{m}$, and a takeoff angle of $45^{\circ}$.

\subsection{Contact resistance measurements}

The contact resistance was measured to evaluate the electrical conductivity between the stainless steel and the carbon paper, which is important for application as a bipolar plate in a fuel cell. The specimen was sandwiched between carbon papers (Toray Industries, TGP-H-120, CP) and electrodes (gold-plated copper plates) were brought into contact from both sides at a pressure of $1 \mathrm{MPa}$. The electrical resistance between the electrodes was measured with a Tsuruga Electric, Model 3569 portable AC $\mathrm{m} \Omega$ meter. The contact resistance is defined as the measured electrical resistance multiplied by the area of the contact surface. 


\subsection{Water contact angle measurement}

The contact angle of a water droplet with the stainless steel surface was measured by using a Kyowa Interface Science, CA-W contact angle measurement system with a $2-\mu \mathrm{L}$ water droplet. Ultrasonic cleaning was conducted in acetone and water before measurement. As a hydrophobic treatment, the specimen was immersed in 2 mass $\% 1 \mathrm{H}, 1 \mathrm{H}, 2 \mathrm{H}, 2 \mathrm{H}-$ perfluorodecyltriethoxysilane (FUJIFILM Wako Pure Chemical, FAS) in hexane for 2 days and then heat treated at $100^{\circ} \mathrm{C}$ for 1 hour. Water contact angle values were the average data of five different points on each specimen.

\section{Results}

\subsection{Heat treatment}

To fabricate mushroom-like nanostructures, only the titanium must be oxidized to form the island-like titanium oxide which becomes the mushroom "cap" (Fig. 1, step 1). In the initial stages of oxidation of stainless steel, fine oxide particles are formed on the surface by nucleation and subsequent growth, and these fine oxide particles combine over time to form an oxide film. ${ }^{26)}$ Thus to form island-like titanium oxide, oxidation of iron and chromium must be suppressed (otherwise their oxides can combine with titanium oxide to form a continuous oxide film, and the mushroomlike nanostructures cannot be fabricated by electrochemical etching in the next process). This selective oxidation of titanium is achieved through control of heat-treatment conditions.

We examined the morphologies of the oxides on the stainless steel surface after different heat treatments; SEM images are shown in Fig. 2. After heat treatment with condition (a), the stainless steel surface was densely covered with oxide particles. In contrast, after condition (b), irregularly shaped oxide particles were dispersed on the stainless steel surface; in some areas, the oxide particles combined and became continuous. After condition (c), the
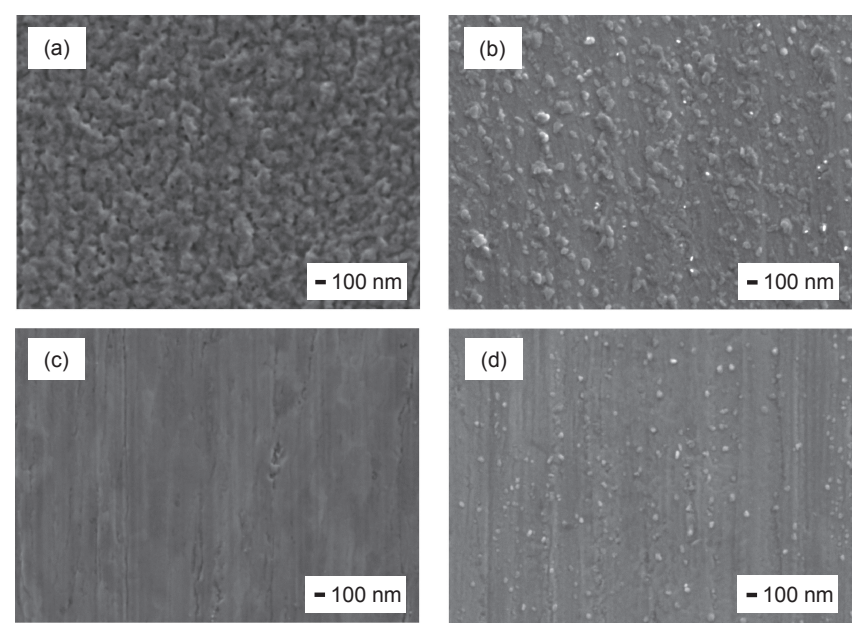

Fig. 2 SEM images of stainless steel surfaces after heat treatment in $75 \mathrm{vol} \% \mathrm{H}_{2}-25 \mathrm{vol} \% \mathrm{~N}_{2}$ (a) at $920^{\circ} \mathrm{C}$ for $5 \mathrm{~s}$ at dew point $-18^{\circ} \mathrm{C}$, (b) at $950^{\circ} \mathrm{C}$ for $5 \mathrm{~s}$ at dew point $-45^{\circ} \mathrm{C}$, (c) at $920^{\circ} \mathrm{C}$ for $5 \mathrm{~s}$ at dew point $-68^{\circ} \mathrm{C}$ using the tubular furnace and (d) at $948^{\circ} \mathrm{C}$ for $1 \mathrm{~s}$ at dew point $-44^{\circ} \mathrm{C}$ using the continuous furnace.

surface appeared similar to that prior to heat treatment. After condition (d), the oxide particles were finer and more islandlike compared with those from condition (b).

Figure 3 shows a cross-section of the oxide particle formed under the condition (d), as observed by TEM. The diameter of the island-like oxide particle was $\sim 90 \mathrm{~nm}$, and the EDX results confirmed that it was mainly composed of titanium oxide.

Thus the morphology of the oxide formed on the stainless steel surface changed significantly depending on the heattreatment conditions. Because the island-like titanium oxide was obtained by heat treatment under condition (d), all subsequent experiments used this heat-treatment condition.

\subsection{Electrochemical etching}

The stainless steel substrate is selectively dissolved by
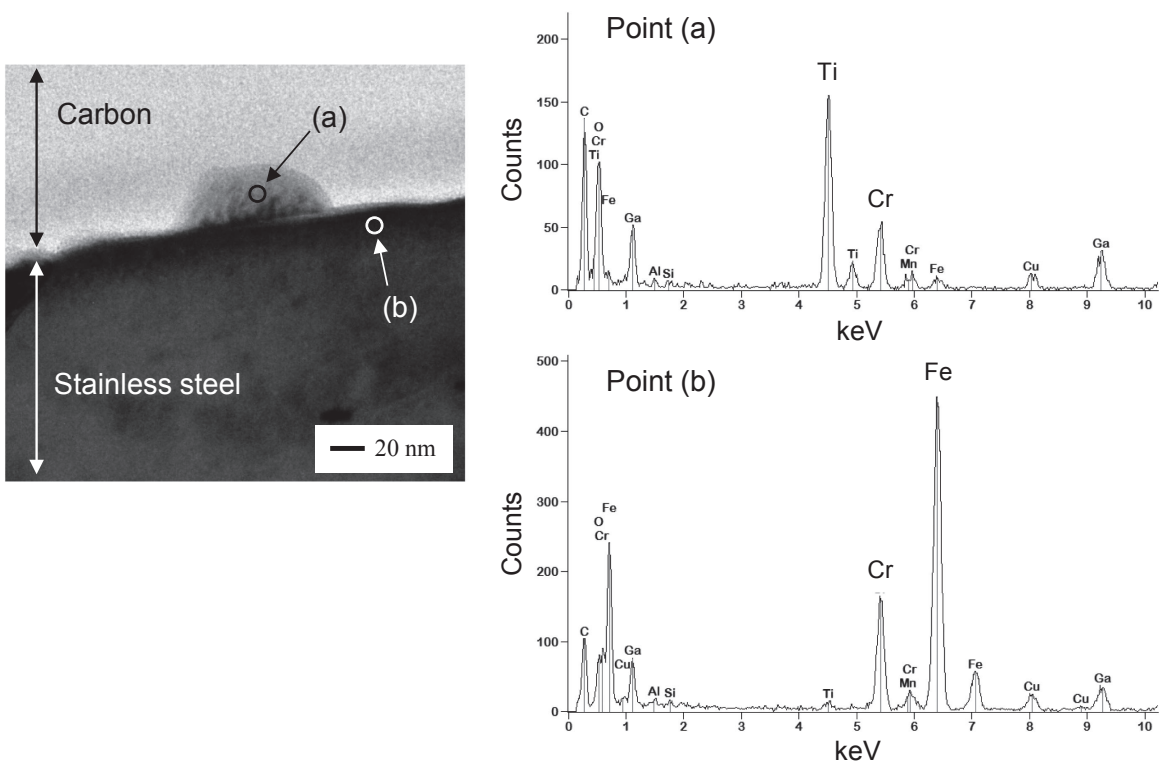

Fig. 3 TEM image of stainless steel cross-section after heat treatment. EDX spectra taken from points (a) and (b) indicated on the image are also shown. Heat treatment: $948^{\circ} \mathrm{C}$ for $1 \mathrm{~s}$ at dew point $-44^{\circ} \mathrm{C}$ using the continuous furnace. A Cu mesh was used as the sample support. 


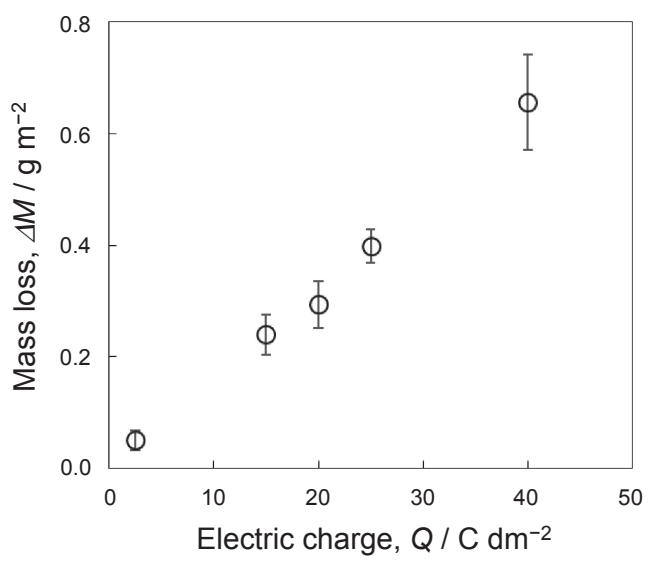

Fig. 4 Electric charge dependence of mass loss during electrochemical etching of heat-treated stainless steels at $0.5 \mathrm{~A} \mathrm{dm}^{-2}$ for $5-80 \mathrm{~s}$ in $30 \mathrm{~g} / \mathrm{L}$ $\mathrm{H}_{2} \mathrm{SO}_{4}$ solution at $40^{\circ} \mathrm{C}$. Heat treatment: $948^{\circ} \mathrm{C}$ for $1 \mathrm{~s}$ at dew point $-44^{\circ} \mathrm{C}$ using the continuous furnace.

electrochemical etching to fabricate the mushroom-like nanostructures (Fig. 1, step 2). The potential-pH diagram ${ }^{27}$ ) shows that $\mathrm{Fe}$ and $\mathrm{Cr}$, the main components of the stainless steel substrate, are dissolved by electrochemical etching under acidic conditions at potentials within the transpassive region of stainless steels. However, because the titanium oxide is stable under acidic conditions at these potentials, the island-like titanium oxide on the stainless steel surface is not dissolved, and remains on the surface. Potential measurement during electrochemical etching found that the etching potential of the stainless steel was $\sim 1.3 \mathrm{~V}$ (vs. $\mathrm{Ag} /$ $\mathrm{AgCl} /$ sat. $\mathrm{KCl}$ ). Therefore, in the electrochemical etching condition of this study, the stainless steel substrate can be dissolved, but the titanium oxide cannot be dissolved.

Next, we examined the control of mass loss in electrochemical etching, specifically the relationship between the electric charge and mass loss, as shown in Fig. 4. Mass loss increases with electric charge during electrochemical etching. Therefore, the mass loss is controlled by the electric charge.

Furthermore, we observed surfaces and cross-sections of the etched stainless steels to investigate the optimum mass loss for the fabrication of mushroom-like nanostructures. Figure 5 shows surface SEM images and cross-sectional TEM images of stainless steels with different mass losses. In the initial stage of electrochemical etching, the mass loss was small (Fig. 5(b), $0.06 \mathrm{~g} \mathrm{~m}^{-2}$ ) and the stem part of the mushroom-like nanostructure was thick and short. As the mass loss increased (Fig. 5(c), $0.31 \mathrm{~g} \mathrm{~m}^{-2}$ ), the stem part became thinner and longer, and the shape of the mushroom-
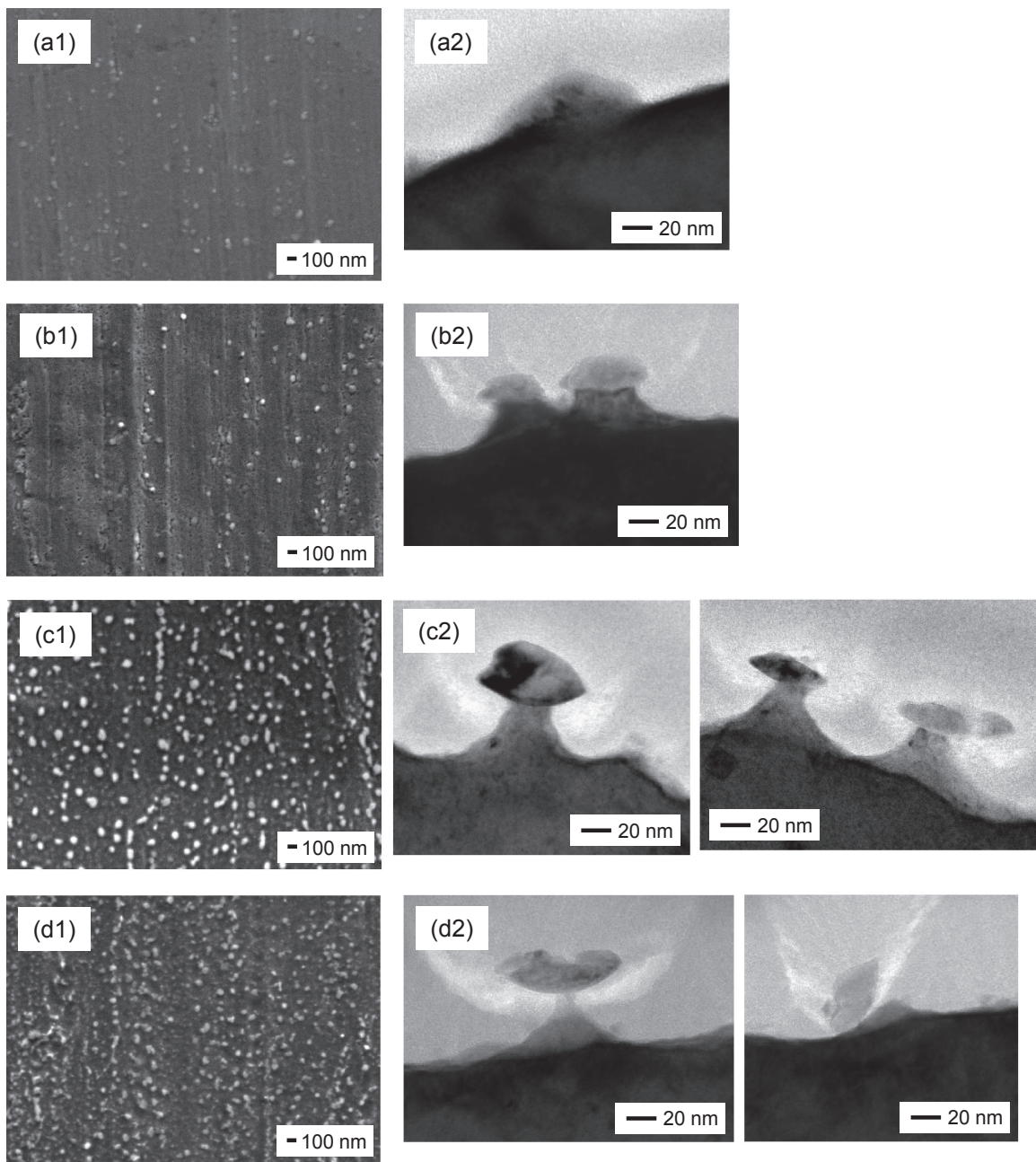

Fig. 5 (a1)-(d1) surface SEM images and (a2)-(d2) cross-sectional TEM images of heat-treated stainless steels before (a) and after electrochemical etching at (b) $0.06 \mathrm{~g} \mathrm{~m}^{-2}$, (c) $0.31 \mathrm{~g} \mathrm{~m}^{-2}$ and (d) $0.57 \mathrm{~g} \mathrm{~m}^{-2}$ at $0.5 \mathrm{~A} \mathrm{dm}^{-2}$ for $5-80 \mathrm{~s}$ in $30 \mathrm{~g} / \mathrm{L} \mathrm{H}_{2} \mathrm{SO}_{4}$ solution at $40^{\circ} \mathrm{C}$. Heat treatment: $948^{\circ} \mathrm{C}$ for $1 \mathrm{~s}$ at dew point $-44^{\circ} \mathrm{C}$ using the continuous furnace. 
like nanostructure became clearer. The mushroom-like nanostructures were dispersed on entire stainless steel surface. As the mass loss increased further (Fig. 5(d), $0.56 \mathrm{~g} \mathrm{~m}^{-2}$ ), the stem part became very thin. A surface structure in which the cap part detached from the stem part was also observed, because of the extreme thinning of the stem part.

The shape of the mushroom-like nanostructures changed depending on the mass loss during electrochemical etching. Controlling the mass loss to $0.31 \mathrm{~g} \mathrm{~m}^{-2}$ (electric charge was $20 \mathrm{C} \mathrm{dm}^{-2}$ ) enabled clear mushroom-like nanostructures to be fabricated on the stainless steel surface. Submicron- to submillimeter-sized mushroom-like structures have been fabricated on material surfaces previously. ${ }^{16-21)}$ However, the structures obtained in this study are less than $100 \mathrm{~nm}$ in size, smaller than those previously reported.

\subsection{Characterization of mushroom-like nanostructures}

The nanostructured stainless steel surface obtained after heat treatment with condition (d) and electrochemical etching with an electric charge of $20 \mathrm{C} \mathrm{dm}^{-2}$ was then characterized in detail.

Figure 6 shows a cross-sectional TEM image and EDX analyses of the mushroom-like nanostructures fabricated on the stainless steel surface. The dimensions of the mushroomlike nanostructure were: cap diameter $\sim 70 \mathrm{~nm}$; cap height $\sim 20 \mathrm{~nm}$; stem diameter $\sim 20 \mathrm{~nm}$ and stem height $\sim 30 \mathrm{~nm}$. The composition of the cap part was almost the same as that of the island-like titanium oxide formed by heat treatment (Fig. 3), which indicates that the island-like titanium oxide became the cap part. The composition of the stem part was the same as that of the stainless steel substrate, implying that the stem part was fabricated by dissolving the stainless steel substrate.

Figure 7 provides more detailed analysis of the mushroomlike nanostructure: a cross-sectional STEM image, EDX, EELS, and electron diffraction results. From the EDX spectrum, the cap part of the mushroom-like nanostructure was mainly composed of titanium oxide and contained small amounts of $\mathrm{Cr}, \mathrm{Mn}$ and $\mathrm{Fe}$. The shape of the Ti- $L_{2,3}$ region in the EELS spectrum is close to that of $\gamma-\mathrm{Ti}_{3} \mathrm{O}_{5}$, and excluded other titanium oxides with different ratios of $\mathrm{Ti}$ and $\mathrm{O}$, such as $\mathrm{TiO}_{2}{ }^{28)}$ In addition, analysis of the electron diffraction pattern identified the titanium oxide as $\gamma-\mathrm{Ti}_{3} \mathrm{O}_{5}$. However, chromium oxide was detected at some points on another cap part. From the EDX and electron diffraction analysis, this chromium oxide was identified as $\mathrm{Cr}_{2} \mathrm{O}_{3}$.

Thus the cap part of the mushroom-like nanostructure was mainly composed of $\gamma-\mathrm{Ti}_{3} \mathrm{O}_{5}$, and the stem part was composed of the stainless steel substrate.

\subsection{Contact resistance}

The contact resistance after heat treatment was $485.1 \mathrm{~m} \Omega \mathrm{cm}^{2}$. This was significantly reduced to $14.8 \mathrm{~m} \Omega \mathrm{cm}^{2}$ for the surface with mushroom-like nanostructures obtained after heat treatment with condition (d) and electrochemical etching with an electric charge of $20 \mathrm{C} \mathrm{dm}^{-2}$.

\subsection{Water contact angle}

As shown in Table 2, the water contact angle after heat treatment was $56^{\circ}$ without FAS coating, and decreased to $44^{\circ}$ upon fabrication of the mushroom-like nanostructures; in other words, the nanostructures improved the hydrophilicity of the uncoated surface. Conversely, with FAS coating, the water contact angle after heat treatment was $109^{\circ}$, but the contact angle increased to $118^{\circ}$ with the mushroom-like nanostructures; in this case, the nanostructures improved the hydrophobicity of the coated surface.

\section{Discussion}

\subsection{Effect of heat-treatment conditions on oxidation behavior}

The morphology of the oxide formed on the stainless steel surface changed significantly depending on heat-treatment
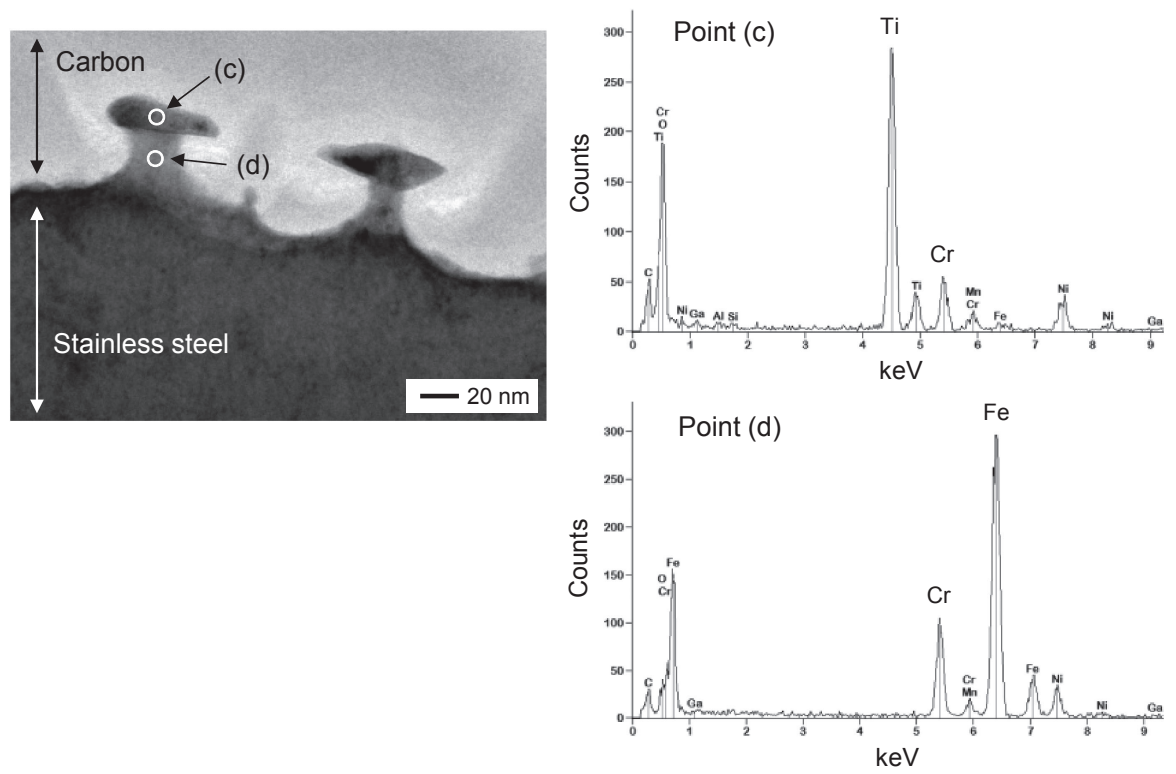

Fig. 6 TEM image of heat-treated stainless steel cross-section after electrochemical etching at $0.5 \mathrm{~A} \mathrm{dm}^{-2}$ for $40 \mathrm{~s}$ in $30 \mathrm{~g} / \mathrm{L} \mathrm{H}_{2} \mathrm{SO}_{4}$ solution at $40^{\circ} \mathrm{C}$. EDX spectra taken from points (c) and (d) indicated on the micrograph are also shown. Heat treatment: $948^{\circ} \mathrm{C}$ for $1 \mathrm{~s}$ at dew point $-44^{\circ} \mathrm{C}$ using the continuous furnace. A Ni mesh was used as the sample support. 
(a)

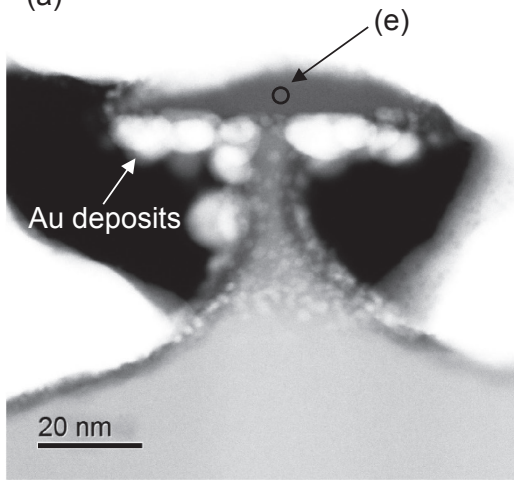

(b)

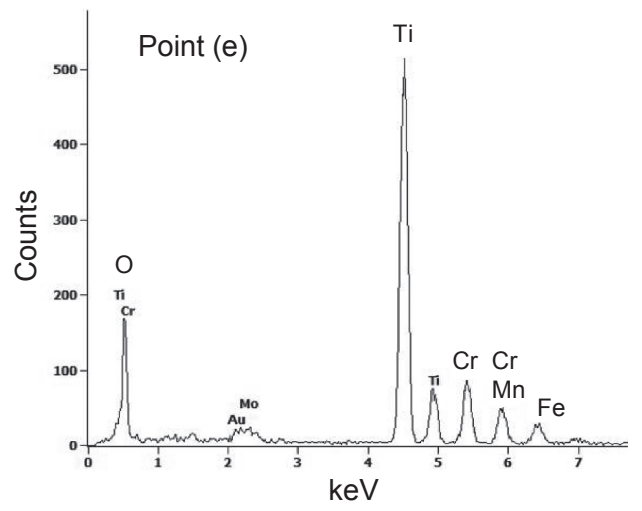

(d)
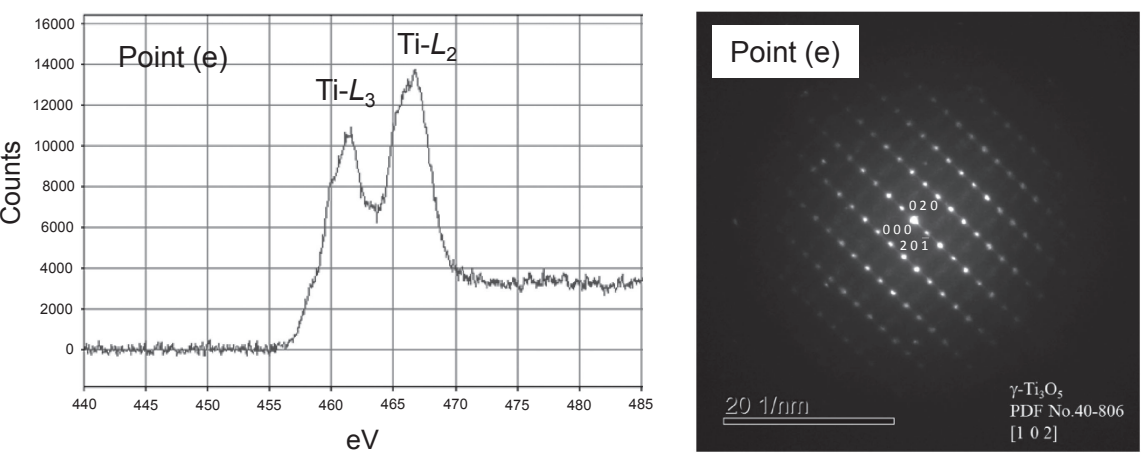

Fig. 7 (a) STEM image of heat-treated stainless steel cross-section after electrochemical etching at $0.5 \mathrm{~A} \mathrm{dm}^{-2}$ for $40 \mathrm{~s}$ in $30 \mathrm{~g} / \mathrm{L} \mathrm{H}_{2} \mathrm{SO}_{4}$ solution at $40^{\circ} \mathrm{C}$, (b) EDX spectrum, (c) Ti- $L_{2,3}$ EELS spectrum and (d) electron diffraction pattern taken from the point "(e)" indicated in (a). Heat treatment: $948^{\circ} \mathrm{C}$ for $1 \mathrm{~s}$ at dew point $-44^{\circ} \mathrm{C}$ using the continuous furnace. A Mo mesh was used as the sample support.

Table 2 Measured and calculated water contact angles on stainless steel without and with FAS coating. Heat treatment: $948^{\circ} \mathrm{C}$ for $1 \mathrm{~s}$ at dew point $-44^{\circ} \mathrm{C}$ using the continuous furnace. Electrochemical etching: $0.5 \mathrm{~A} \mathrm{dm}^{-2}$ for $40 \mathrm{~s}$ in $30 \mathrm{~g} / \mathrm{L} \mathrm{H}_{2} \mathrm{SO}_{4}$ solution at $40^{\circ} \mathrm{C}$.

\begin{tabular}{llcc}
\hline & & \multicolumn{2}{c}{ Water contact angle, $\theta /{ }^{\circ}$} \\
& & Without FAS & With FAS \\
\hline After heat treatment & $\theta$ (measured) & 56 & 109 \\
After electrochemical etching & $\theta$ (measured) & 44 & 118 \\
& $\theta_{\mathrm{w}}$ (calculated) & 37 & 118 \\
\hline
\end{tabular}

conditions, with island-like titanium oxide being obtained under condition (d) (Fig. 2 and 3). In this section, we consider the effect of heat-treatment conditions on the oxidation behavior of the stainless steel surface based on thermodynamic equilibrium theory. The oxidation proceeds when the partial pressure of oxygen in the heat-treatment atmosphere is higher than the dissociation pressure of oxygen $\left(\mathrm{PO}_{2}\right)$ in equilibrium with the metal and its oxide. However, when the partial pressure of oxygen in the heat-treatment atmosphere is lower than the equilibrium dissociation pressure of oxygen, the metal oxide is reduced.

Figure 8 shows a $T$ - $\log P \mathrm{O}_{2}$ diagram of the stainless steel obtained from the following eqs. (1)-(5) for typical oxidation reactions of $\mathrm{Fe}, \mathrm{Cr}$ and $\mathrm{Ti}$. The calculation method, and values for standard enthalpy, standard entropy and activity are given in the literature. ${ }^{29-32)}$

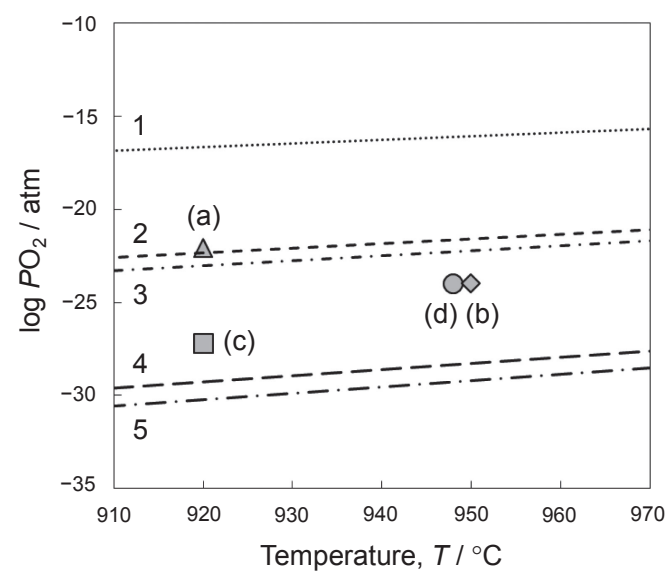

Fig. $8 T$ - $\log \mathrm{PO}_{2}$ diagram of the stainless steel, calculated according to the following formulae: line $1: 2 \mathrm{Fe}(\mathrm{s})+\mathrm{O}_{2}(\mathrm{~g})=2 \mathrm{FeO}(\mathrm{s})$ line $2: 1 / 2 \mathrm{Fe}(\mathrm{s})+$ $\mathrm{Cr}(\mathrm{s})+\mathrm{O}_{2}(\mathrm{~g})=1 / 2 \mathrm{FeCr}_{2} \mathrm{O}_{4}(\mathrm{~s})$ line $3: 4 / 3 \mathrm{Cr}(\mathrm{s})+\mathrm{O}_{2}(\mathrm{~g})=2 / 3 \mathrm{Cr}_{2} \mathrm{O}_{3}(\mathrm{~s})$ line 4: $\mathrm{Ti}(\mathrm{s})+\mathrm{O}_{2}(\mathrm{~g})=\mathrm{TiO}_{2}(\mathrm{~s})$ line 5: $6 / 5 \mathrm{Ti}(\mathrm{s})+\mathrm{O}_{2}(\mathrm{~g})=2 / 5 \mathrm{Ti}_{3} \mathrm{O}_{5}(\mathrm{~s})$. The partial pressures of oxygen for each of the heat-treatment conditions (a)-(d) are also shown: (a) $920^{\circ} \mathrm{C}$ at dew point $-18^{\circ} \mathrm{C}$, (b) $950^{\circ} \mathrm{C}$ at dew point $-45^{\circ} \mathrm{C}$, (c) $920^{\circ} \mathrm{C}$ at dew point $-68^{\circ} \mathrm{C}$ and (d) $948^{\circ} \mathrm{C}$ at dew point $-44^{\circ} \mathrm{C}$ in $75 \mathrm{vol} \% \mathrm{H}_{2}-25 \mathrm{vol} \% \mathrm{~N}_{2}$.

$$
\begin{aligned}
& 2 \mathrm{Fe}(\mathrm{s})+\mathrm{O}_{2}(\mathrm{~g})=2 \mathrm{FeO}(\mathrm{s}) \\
& 1 / 2 \mathrm{Fe}(\mathrm{s})+\mathrm{Cr}(\mathrm{s})+\mathrm{O}_{2}(\mathrm{~g})=1 / 2 \mathrm{FeCr}_{2} \mathrm{O}_{4}(\mathrm{~s}) \\
& 4 / 3 \mathrm{Cr}(\mathrm{s})+\mathrm{O}_{2}(\mathrm{~g})=2 / 3 \mathrm{Cr}_{2} \mathrm{O}_{3}(\mathrm{~s}) \\
& \mathrm{Ti}(\mathrm{s})+\mathrm{O}_{2}(\mathrm{~g})=\mathrm{TiO}_{2}(\mathrm{~s}) \\
& 6 / 5 \mathrm{Ti}(\mathrm{s})+\mathrm{O}_{2}(\mathrm{~g})=2 / 5 \mathrm{Ti}_{3} \mathrm{O}_{5}(\mathrm{~s})
\end{aligned}
$$


The partial pressures of oxygen for each heat-treatment condition (a)-(d) are also shown in Fig. 8.

In condition (a), because the partial pressure of oxygen in the heat-treatment atmosphere is high and $\mathrm{Fe}$ and $\mathrm{Cr}$ are oxidized, the island-like titanium oxide is not formed. In fact, the oxide on the stainless steel surface under this condition (Fig. 2(a)) was identified as chromium oxide by EDX and XRD.

At the partial pressure of oxygen used for conditions (b) and (d), Ti is oxidized, however $\mathrm{Fe}$ and $\mathrm{Cr}$ are not oxidized. In Fig. 2(b) and (d), oxide particles were seen on both of these surfaces. However, the oxide particles in Fig. 2(d) were finer and more island-like than those in Fig. 2(b). We examined the surface composition of the stainless steel in both cases using XPS. The Ti concentration on the surface was 1 at $\%$ for condition (d) and 6 at $\%$ for condition (b), although the $\mathrm{Fe}$ and $\mathrm{Cr}$ concentrations are almost the same for both surfaces. These results imply that the oxidation of titanium can proceed on the stainless steel surface under condition (b). This difference in surface morphology could be caused by difference in the heat-treatment furnaces used for conditions (b) and (d). The continuous furnace in condition (d) has a faster heating rate and heating time than those of the tubular furnace in condition (b). Therefore, oxide particles cannot grow under condition (d), so that the separated, island-like form of titanium oxides was maintained. However, under condition (b), the shape of the oxide particles can be large and irregular because of the greater oxidation of $\mathrm{Ti}$ and merging of the oxide particles may occur due to the longer time taken for the heating process. The diffusion coefficient of $\mathrm{Ti}$ is about 100 times higher than that of $\mathrm{Cr}$ in ferritic iron. ${ }^{33)}$ From the diffusion perspective, Ti can be rapidly oxidized.

At the partial pressure of oxygen under condition (c), Ti is oxidized as in conditions (b) and (d). However, no oxide particles were observed on the stainless steel surface (Fig. 2(c)). Because hydrogen and nitrogen are present at the very low dew point in condition (c), reducibility increases and nitridation can occur. Figure 9 shows the results of XPS analysis of the stainless steel surface after heat treatment under conditions (b) and (c). The intensity of the peak assigned to nitrides ${ }^{34)}$ was high for condition (c). These results indicate that a nitride is formed on the surface; the nitride is likely to be mostly chromium nitride. Therefore, in condition (c), this nitride formed on the stainless steel surface may suppress the oxidation of Ti. Furthermore, because the partial pressure of oxygen in the heat-treatment atmosphere is very low, the titanium oxide may not grow. In fact, the $\mathrm{O}$ intensity in condition (c) was lower than that in condition (b), and the intensity of the peak attributed to titanium oxide was also lower.

Next, we consider the formation of $\gamma-\mathrm{Ti}_{3} \mathrm{O}_{5}$ and $\mathrm{Cr}_{2} \mathrm{O}_{3}$ in the cap part of the mushroom-like nanostructure. Magnéli phase titanium oxide $\mathrm{Ti}_{n} \mathrm{O}_{2 n-1}(n=3-10)$ is produced by heating $\mathrm{TiO}_{2}$ with metallic titanium in an inert atmosphere or by reducing $\mathrm{TiO}_{2}$ at high temperature using a reducing agent such as hydrogen gas. ${ }^{35)}$ Tanaka et al. ${ }^{36)}$ calcined $\mathrm{TiO}_{2}$ at $964^{\circ} \mathrm{C}$ for 5 hours in a hydrogen atmosphere to obtain $\mathrm{Ti}_{3} \mathrm{O}_{5}$. As shown in Fig. 8, the thermodynamic equilibrium consideration suggests that $\mathrm{TiO}_{2}$ is also formed. However
$\mathrm{Ti}_{3} \mathrm{O}_{5}$ can be easily formed due to the reducing atmosphere containing hydrogen at the low partial pressure of oxygen. We also identified $\mathrm{Cr}_{2} \mathrm{O}_{3}$ within the cap part. Although no corresponding phase was identified, the EDX analysis of the cap part (Fig. 7) found small amounts of Fe and Mn, which are probably also present as oxides. Figure 8 shows that, based on thermodynamic equilibrium considerations, $\mathrm{Cr}$ is not expected to be oxidized under condition (d); however $\mathrm{Cr}$, $\mathrm{Fe}$, and $\mathrm{Mn}$ were actually oxidized. In general, an oxide film formed by bright annealing includes an oxide formed by nonequilibrium thermodynamic reactions during the rapid heating process of the stainless steel. ${ }^{37)}$ Because the heat treatment under the condition (d) is also rapid, the oxide formed here could include the oxides formed through nonequilibrium thermodynamic reactions.

\subsection{Selective dissolution by electrochemical etching}

Mushroom-like nanostructures were fabricated on the stainless steel surface by controlling the mass loss during electrochemical etching to $\sim 0.3 \mathrm{~g} \mathrm{~m}^{-2}$. As shown in Fig. 5-7, these mushroom-like nanostructures vary in shape. In this section, we consider the dissolution mechanism during electrochemical etching.

West et $a .^{38)}$ and Madore et al. ${ }^{39)}$ simulated the shape change during through-mask electrochemical micromachining from the current distribution under mass-transfer limited conditions. The shape of the cavity was also evaluated in terms of the undercut $(u)$ and the etch factor $(E F)$. Figure 10 shows a schematic illustration of shape evolution during electrochemical etching of a metal through an insulating mask. On the figure, $d$ is the maximum etching depth, $h$ is the mask thickness, $w$ is the half-width of the mask-opening, and $w^{\prime}$ is the maximum half-width of the final etched cavity. $u$ is given by $w^{\prime}-w$, and $E F$ is represented by $d / u$, and indicates the anisotropy of the etching. When $E F=1$, isotropic etching occurs. The anisotropy increases as the value of $E F$ increases, indicating that etching proceeds locally.

In this study, the island-like titanium oxide becomes the insulating mask. However, the island-like titanium oxide was nonuniformly dispersed on the stainless steel surface, and its shape also varied. Therefore, as an example, we evaluated the shape of the two-dimensional cavity in the cross-section between two mushroom-like nanostructures, obtained in the cross-sectional TEM image of Fig. 6.

Figure 11 shows the cavity shape profile (dotted line) and shape parameters for the cavity in Fig. 6. Although the shapes of the two mushroom nanostructures were slightly different, the shape profile between them is close to hemispherical. The undercuts were also observed, and $E F$ was estimated to be 1.8. Because $E F>1$, the undercut is suppressed and etching proceeds more rapidly in the direction normal to the stainless steel surface. The aspect ratio of the mask opening $(h / w)$ is also an important parameter. For a high aspect ratio $(h / w>0.5)$, the current distribution is practically uniform. As the etching proceeds, the maximum in the current distribution becomes located at the center of the cavity and remains there. ${ }^{38)}$ Because $h / w$ was estimated to be 0.7 , the current distribution could be uniform and thus the shape was almost hemispherical. As the etching proceeds further, $E F$ approaches isotropic etching $(E F=1)$. Therefore, 
(a) $\mathrm{N} 1 \mathrm{~s}$

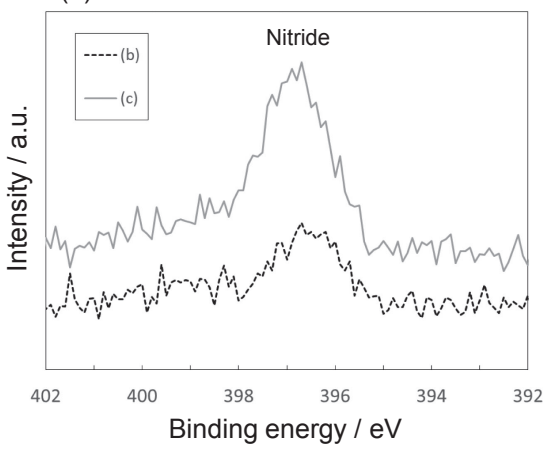

(c) $\operatorname{Cr} 2 p_{3 / 2}$

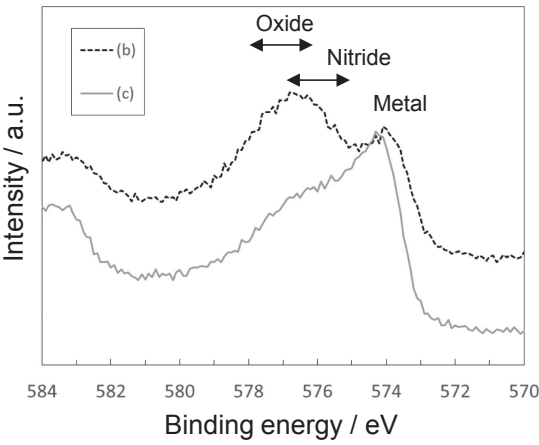

(e) $\mathrm{Fe} 2 \mathrm{p}_{3 / 2}$

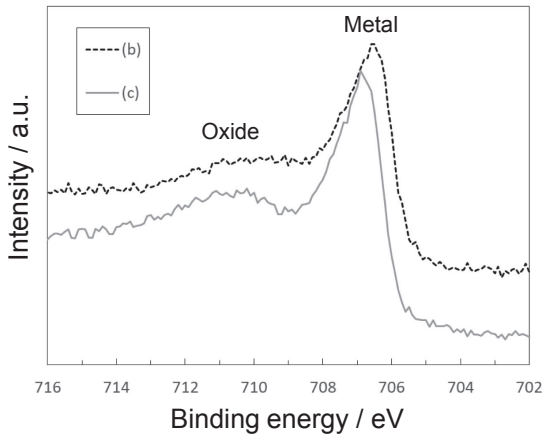

(b) $01 \mathrm{~s}$

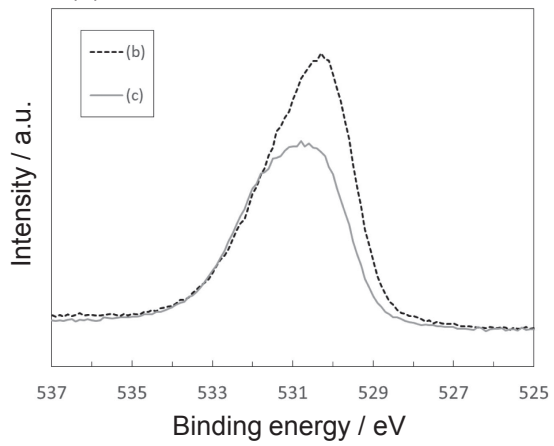

(d) $\mathrm{Ti} 2 \mathrm{p}_{3 / 2}$

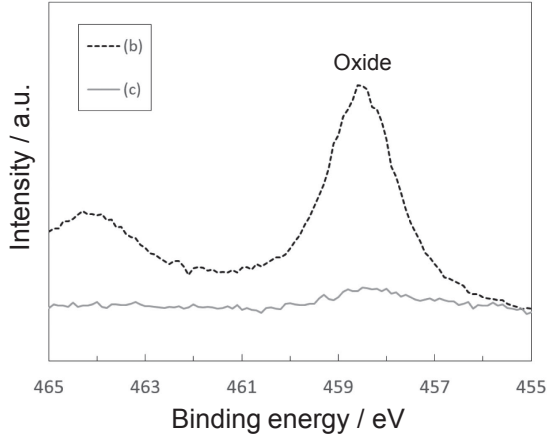

Fig. 9 XPS spectra of (a) $\mathrm{N} 1 \mathrm{~s}$, (b) O 1s, (c) $\mathrm{Cr} 2 \mathrm{p}_{3 / 2}$, (d) $\mathrm{Ti} 2 \mathrm{p}_{3 / 2}$ and (e) $\mathrm{Fe} 2 \mathrm{p}_{3 / 2}$ for stainless steel surfaces after heat treatment in $75 \mathrm{vol} \% \mathrm{H}_{2}-25 \mathrm{vol} \% \mathrm{~N}_{2}$ in the tubular furnace. Dashed lines (b) $950^{\circ} \mathrm{C}$ for $5 \mathrm{~s}$ at dew point $-45^{\circ} \mathrm{C}$; solid lines (c) $920^{\circ} \mathrm{C}$ for $5 \mathrm{~s}$, dew point $-68^{\circ} \mathrm{C}$.

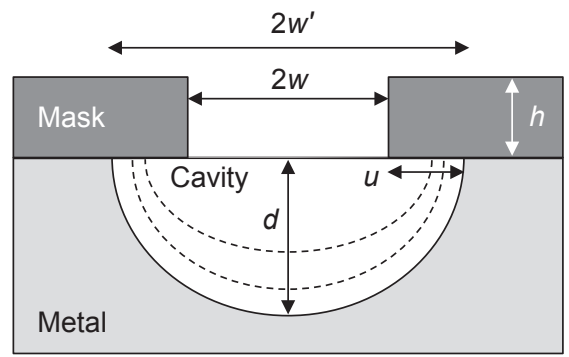

Fig. 10 Schematic illustration of shape evolution during electrochemical etching of a metal through an insulating mask. Maximum etch depth $(d)$, mask thickness $(h)$, half-width of the mask-opening $(w)$, maximum halfwidth of the final etched cavity $\left(w^{\prime}\right)$, undercut $(u)$.

the undercut increases and the mushroom-like nanostructure cannot be maintained, as shown in Fig. 5(d2).

However, the shape parameters shown in Fig. 11 vary depending on the shape of the island-like titanium oxide formed by heat treatment and the distance between adjacent

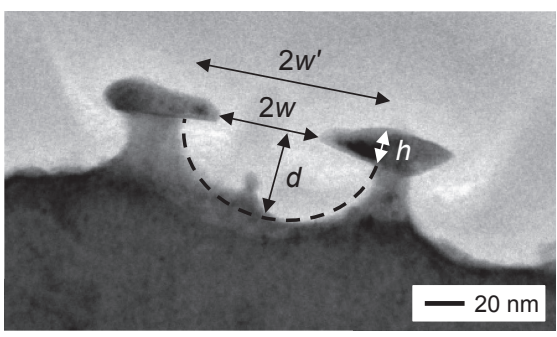

Fig. 11 The cavity shape profile (dotted line) and shape parameters for the cross-section of the mushroom-like nanostructures of Fig. 6. Maximum etch depth $(d)$, mask thickness $(h)$, half-width of the mask-opening $(w)$, maximum half-width of the final etched cavity $\left(w^{\prime}\right)$.

island-like titanium oxides. Therefore, $E F$ and $h / w$ are different for each mushroom-like nanostructure, and the current distribution during electrochemical etching is significantly affected by the shape and distance of the surrounding mushroom-like nanostructures. From these 
considerations, the shapes of mushroom-like nanostructures in this study can vary.

\subsection{Contact resistance reducing mechanism}

Generally, stainless steel exhibits a high contact resistance because of the passive film on its surface. In fact, the contact resistance before heat treatment was as high as $1774 \mathrm{~m} \Omega \mathrm{cm}^{2}$. However, the contact resistance was significantly reduced to $14.8 \mathrm{~m} \Omega \mathrm{cm}^{2}$ by fabricating the mushroom-like nanostructures. Therefore, we examined the mechanism of this contact resistance reduction.

The contact resistance is expressed as the contribution of the constriction resistance and the surface film resistance as shown by the following equation. ${ }^{40)}$

$$
R=\left(\rho_{\mathrm{s}}+\rho_{\mathrm{c}}\right) / 4 a n+\rho_{\mathrm{f}} d / \pi a^{2} n
$$

where $\rho_{\mathrm{s}}, \rho_{\mathrm{c}}$ and $\rho_{\mathrm{f}}$ are the electrical resistivity of the stainless steel, the carbon paper and the surface film, respectively, $a$ is the radius of the real contact area, $n$ is the number of contact points, and $d$ is the thickness of the surface film.

According to eq. (6), the reduction of contact resistance could be attributed to an increase in the electrical conductivity of the surface film and/or an increase in the contact area by the fabrication of mushroom-like nanostructures on the stainless steel surface.

First, we investigated the effect of the electrical conductivity of the surface film-the cap part of the mushroom-like nanostructure-which is primarily $\gamma-\mathrm{Ti}_{3} \mathrm{O}_{5}$. Tanaka et al. ${ }^{36)}$ reported that the electrical conductivity of $\gamma-\mathrm{Ti}_{3} \mathrm{O}_{5}$ is $4.7 \mathrm{~S} \mathrm{~cm}^{-1}$ at $54^{\circ} \mathrm{C}$, and it has a metallic property at room temperature. Therefore, $\gamma-\mathrm{Ti}_{3} \mathrm{O}_{5}$ has a far higher electrical conductivity than those of $\mathrm{TiO}_{2}\left(8.3 \times 10^{-5} \mathrm{~S} \mathrm{~cm}^{-1}\right.$ at $\left.800^{\circ} \mathrm{C}\right)$ or $\mathrm{Cr}_{2} \mathrm{O}_{3}\left(7.7 \times 10^{-4} \mathrm{~S} \mathrm{~cm}^{-1}\right.$ at $\left.350^{\circ} \mathrm{C}\right){ }^{41)}$ Thus the reduction in the contact resistance can be attributed to the electrically conductive $\gamma-\mathrm{Ti}_{3} \mathrm{O}_{5}$ on the stainless steel surface.

Second, we consider the effect of contact area between the stainless steel surface and the carbon paper. If the main reason for the change in contact resistance was that the electrical conductivity of the surface film had changed, then the contact resistance should be reduced after the electrically conductive $\gamma-\mathrm{Ti}_{3} \mathrm{O}_{5}$ had formed on the stainless steel surface after heat treatment. However, the contact resistance after heat treatment was still high. Therefore, we have to consider the effect of the contact area in addition to that of the electrical conductivity of the surface film. We note that the contact resistance was significantly reduced after electrochemical etching. We consider that this result is caused by the protrusion of $\gamma-\mathrm{Ti}_{3} \mathrm{O}_{5}$ from the stainless steel surface after electrochemical etching. Because the carbon paper is composed of random carbon fibers, ${ }^{2)}$ the protruding $\gamma-\mathrm{Ti}_{3} \mathrm{O}_{5}$ can more easily contact the carbon fiber. Therefore, the contact area between $\gamma-\mathrm{Ti}_{3} \mathrm{O}_{5}$ and carbon fibers can increase. Yanagimoto $^{42)}$ showed that the contact area ratio between the bipolar plate surface and the carbon paper significantly affects the contact resistance. In addition, the protruding $\gamma$ $\mathrm{Ti}_{3} \mathrm{O}_{5}$ may pierce the carbon fiber to form strong electrical contact. In summary, the protrusions of electrically conductive $\gamma-\mathrm{Ti}_{3} \mathrm{O}_{5}$, which constitute the cap parts of the mushroom-like nanostructures, can contribute to the reduction of the contact resistance.

\subsection{Water contact state}

As shown in Table 2, we did not obtain a superhydrophobic surface by fabricating the mushroom-like nanostructures and applying the FAS coating on the stainless steel surface. In this section, we consider the contact condition between the mushroom-like nanostructures and the water droplet.

Wenzel $^{43)}$ showed that the apparent contact angle obeys the following equation when the interface between the material surface and the droplet is perfectly continuous.

$$
\cos \theta_{\mathrm{w}}=r \cos \theta
$$

$r$ is the roughness factor, $\theta$ is the contact angle at a smooth surface.

According to eq. (7), $\theta_{\mathrm{w}}$ is larger than $\theta$ when $\theta>90^{\circ}$, and smaller than $\theta$ when $\theta<90^{\circ}$.

If an air pocket exists between the material surface and the droplet (also known as the Cassie-Baxter state), the contact angle $\theta_{\mathrm{C}-\mathrm{B}}$ is given by eq. (8). ${ }^{44)}$

$$
\cos \left(\theta_{\mathrm{C}-\mathrm{B}}\right)=f((\cos \theta)+1)-1
$$

$f$ is the fraction of the area where the material surface is in contact with the droplet.

In this state, $\theta_{\mathrm{C}-\mathrm{B}}$ is always larger than $\theta$, and the contact angle $\theta_{\mathrm{C}-\mathrm{B}}$ will be close to $180^{\circ}$ as $f$ becomes smaller.

As shown in Table 2, the fabrication of mushroom-like nanostructures decreased the water contact angle on the hydrophilic surface without FAS coating, and increased the water contact angle on the hydrophobic surface with FAS coating. These results and eq. (7) indicate that the contact between mushroom-like nanostructures and the water droplet is in the Wenzel state. Water contact angles, $\theta_{\mathrm{w}}$, calculated from eq. (7) are shown in Table 2. The roughness factor was estimated from the cross-sectional TEM image (Fig. 6) as 1.42. ${ }^{16)}$ The calculated values are in good agreement with the measured ones.

The mushroom-like nanostructures fabricated in this study did not exhibit superhydrophobicity. To obtain a superhydrophobic surface with a water contact angle of more than $150^{\circ}$, a Cassie-Baxter state is required between the mushroom-like nanostructures and the water droplet. Further study is necessary to maintain the air pocket between the surface and the water droplet. For example, the height of the mushroom-like nanostructures might be able to be increased by optimizing the Ti content, heat-treatment conditions, and electrochemical etching conditions.

\section{Conclusions}

First, we fabricated fine mushroom-like nanostructures on the stainless steel surface by heat treatment under an atmosphere with low partial pressure of oxygen, followed by electrochemical etching. The island-like titanium oxide was formed on the Ti-containing stainless steel surface by selective oxidation during heat treatment. This island-like titanium oxide became the cap part of the mushroom-like nanostructure and the stem part was fabricated by selective dissolution during electrochemical etching. The cap part of the mushroom-like nanostructure was mainly composed of $\gamma-\mathrm{Ti}_{3} \mathrm{O}_{5}$, and the stem part was composed of the stainless steel substrate. 
Second, we obtained a highly functional and multifunctional stainless steel surface. The contact resistance was significantly reduced by the fabrication of mushroom-like nanostructures. The protrusions of electrically conductive $\gamma-\mathrm{Ti}_{3} \mathrm{O}_{5}$ can contribute to the reduction of the contact resistance. In addition, the mushroom-like nanostructures improved the hydrophilicity of the surface without FAS coating, but improved the hydrophobicity of the surface with FAS coating. The contact between the stainless steel surface and the water droplet is in the Wenzel state. The mushroomlike nanostructures obtained in this study are expected to be useful in various fields, including as the bipolar plates for polymer electrolyte fuel cells.

\section{REFERENCES}

1) T. Fukutsuka, T. Yamaguchi, S. Miyano, Y. Matsuo, Y. Sugie and Z. Ogumi: J. Power Sources 174 (2007) 199-205.

2) A. Kraytsberg, M. Auinata and Y. Ein-Eli: J. Power Sources 164 (2007) 697-703.

3) R. Blossey: Nat. Mater. 2 (2003) 301-306.

4) S. Nishimoto and B. Bhushan: RSC Adv. 3 (2013) 671-690.

5) A.J. Scardino, H. Zhang, D.J. Cookson, R.N. Lamb and R. de Nys: Biofouling 25 (2009) 757-767.

6) X. Lu, Y. Peng, L. Ge, R. Lin, Z. Zhu and S. Liu: J. Membr. Sci. 505 (2016) 61-69.

7) Y. Chen, Y. Zhang, L. Shi, L. Jing, Y. Xin, T. Yang and Z. Guo: Appl. Phys. Lett. 101 (2012) 033701

8) L. Shen, B. Wang, J. Wang, J. Fu, C. Picart and J. Ji: ACS Appl. Mater. Interfaces 4 (2012) 4476-4483.

9) X. Chen, R. Ma, H. Zhou, X. Zhou, L. Che, S. Yao and Z. Wang: Sci. Rep. 3 (2013) 2515.

10) R. Truesdell, A. Mammoli, P. Vorobieff, F. Swol and C.J. Brinker: Phys. Rev. Lett. 97 (2006) 044504.

11) D. Song, R.J. Daniello and J.P. Rothstein: Exp. Fluids 55 (2014) 17831788 .

12) A.M.A. Mohamed, A.M. Abdullah and N.A. Younan: Arab. J. Chem. 8 (2015) 749-765.

13) T. Nishino, M. Meguro, K. Nakamae, M. Matsushita and Y. Ueda: Langmuir 15 (1999) 4321-4323.

14) A. Tuteja, W. Choi, M. Ma, J.M. Mabry, S.A. Mazzella, G.C. Rutledge, G.H. McKinley and R.E. Cohen: Science 318 (2007) 1618-1622.

15) A. Tuteja, W. Choi, J.M. Mabry, G.H. McKinley and R.E. Cohen: Proc. Natl. Acad. Sci. USA 105 (2008) 18200-18205.

16) P.B. Weisensee, E.J. Torrealba, M. Raleigh, A.M. Jacobi and W.P. King: J. Micromech. Microeng. 24 (2014) 095020.
17) S.M. Kang, S.M. Kim, H.N. Kim, M.K. Kwak, D.H. Tahk and K.Y. Suh: Soft Matter 8 (2012) 8563-8568.

18) S.E. Lee, H. Kim, S. Lee and D. Choi: Langmuir 29 (2013) 8070-8075.

19) M.H. Kwon, H.S. Shinb and C.N. Chu: Appl. Surf. Sci. 288 (2014) $222-228$.

20) X. Chen, J.A. Weibel and S.V. Garimella: Sci. Rep. 5 (2015) 17110.

21) A. Mozalev, H. Habazaki and J. Hubálek: Electrochim. Acta 82 (2012) 90-97.

22) A. Kasuga, A. Koyama, K. Nakayama, D. Kowalski, C. Zhu, Y. Aoki and H. Habazaki: ISIJ Int. 59 (2019) 345-350.

23) J. Kim, A. Mirzaei, H.W. Kim and S.S. Kim: Appl. Surf. Sci. 439 (2018) 598-604.

24) C. Lee, A. Kim and J. Kim: Surf. Coat. Tech. 264 (2015) 127-131.

25) T. Ishii, K. Ishii, H. Ota and C. Kami: ISIJ Int. 55 (2015) 1091-1099.

26) I. Saeki, H. Konno, R. Furuichi, T. Nakamura, K. Mabuchi and M. Itoh: J. Japan Inst. Metals 61 (1997) 416-423.

27) M. Pourbaixa: Atlas of Electrochemical Equilibria in Aqueous Solutions, (Natl. Asoc. of Corrosion Eng., Houston, 1974).

28) E. Stoyanov, F. Langenhorst and G. Steinle-Neumann: Am. Mineral. 92 (2007) 577-586.

29) T. Yamazaki, T. Zaizen, S. Asami and T. Somura: Tetsu-to-Hagané 69 (1983) 126-135.

30) M.W. Chase, Jr., C.A. Davies, J.R. Downey, Jr., D.J. Frurip, R.A. McDonald and A.N. Syverud: JANAF Thermochemical Tables Third Edition Part II, Cr-Zn, (American Chemical Society and American Institute of Physics, New York, 1986).

31) S.E. Ziemniak, L.M. Anovitz, R.A. Castelli and W.D. Porter: J. Chem. Thermodyn. 39 (2007) 1474-1492.

32) Y. Jeannin, C. Mannerskants and F.D. Richardson: Trans. Metall. Soc. AIME 227 (1963) 300-305.

33) The Japan Institute of Metals and Materials: Metals data book 4th ed., (Maruzen, Tokyo, 2004) pp. 20-22.

34) A. Lippitz and T. Hübert: Surf. Coat. Tech. 200 (2005) 250-253.

35) F.C. Walsh and R.G.A. Wills: Electrochim. Acta 55 (2010) 6342-6351.

36) K. Tanaka, T. Nasu, Y. Miyamoto, N. Ozaki, S. Tanaka, T. Nagata, F. Hakoe, M. Yoshikiyo, K. Nakagawa, Y. Umeta, K. Imoto, H. Tokoro, A. Namai and S. Ohkoshi: Cryst. Growth Des. 15 (2015) 653-657.

37) S. Kiya: Zairyo-to-Kankyo 47 (1998) 124-130.

38) A.C. West, C. Madore, Mi. Matlosz and D. Landolt: J. Electrochem. Soc. 139 (1992) 499-506.

39) C. Madore, O. Piotrowski and D. Landolt: J. Electrochem. Soc. 146 (1999) 2526-2532.

40) R. Holm: Electric Contacts: Theory and Application 4th ed., (SpringerVerlag, Berlin/Heidelberg/New York, 1967).

41) G.V. Samsonov: The Oxide Handbook, (IFI/PLENUM, New York, 1973) pp. 269-270.

42) H. Yanagimoto: J. Surf. Finish. Soc. Jpn. 71 (2020) 17-20

43) R.N. Wenzel: Ind. Eng. Chem. 28 (1936) 988-994.

44) A.B.D. Cassie and S. Baxter: Trans. Faraday Soc. 40 (1944) 546-551. 